\title{
The effects of dietary carbohydrate sources and forms on metabolic response and intestinal microbiota in sea bass juveniles, Dicentrarchus labrax
}

\author{
François-Joël Gatesoupe ${ }^{\mathrm{a}, *}$, Christine Huelvan ${ }^{\mathrm{b}}$, Nicolas Le Bayon ${ }^{\mathrm{b}}$, Armelle Sévère ${ }^{\mathrm{b}}$, \\ Inga Marie Aasen ${ }^{c}$, Kristin F. Degnes ${ }^{c}$, David Mazurais ${ }^{b}$, Stéphane Panserat ${ }^{a}$, \\ José L. Zambonino-Infante ${ }^{b}$, Sadasivam J. Kaushik ${ }^{a}$
}

\author{
a INRA, UR 1067, Nutrition, Métabolisme, Aquaculture, 64310 Saint-Pée-sur-Nivelle, France \\ b Ifremer, Unité de Physiologie Fonctionnelle des Organismes Marins, LEMAR UMR 6539, Ifremer, Centre de \\ Brest, Laboratoire PFOM/ARN, BP 70, 29280 Plouzané, France \\ ${ }^{\mathrm{C}}$ SINTEF Materials and Chemistry, NO-7465 Trondheim, Norway

\begin{abstract}
*: Corresponding author : François-Joël Gatesoupe, Tel.: + 33298224389 ; fax: + 33298224366 ; email address : Joel.Gatesoupe@ifremer.fr Christine.Huelvan@ifremer.fr ; Nicolas.Le.Bayon@ifremer.fr ; Armelle.Severe@ifremer.fr ; Inga.M.Aasen@sintef.no ; Kristin.F.Degnes@sintef.no ; David.Mazurais@ifremer.fr ; panserat@st-pee.inra.fr ; Jose.Luis.Zambonino@ifremer.fr ; kaushik@st-pee.inra.fr
\end{abstract}

\begin{abstract}
:
The aim of this work was to investigate the catabolic process of three kinds of dietary carbohydrates in the gut of sea bass juveniles, with the possible contribution of the intestinal microbiota to the nutrition of the host, and the subsequent effects on intermediary metabolism. A first diet contained waxy maize (99\% amylopectin), a highly digestible form of starch. A second diet was less quickly digestible due to its high amylose content of resistant starch. Two other diets contained fibre instead of starch, either only cellulose as control, or also other non-starch polysaccharides brought by lupin meal. The effect of the diets on the host confirmed previous results, with the stimulation of glucose storage in the liver in sea bass fed the starchy diets, which caused a significant increase in liver weight, while lupin meal caused an increase in visceral mass. Glycaemia was higher $7 \pm 1 \mathrm{~h}$ after the last meal in the group fed resistant starch, compared to the other dietary groups, while the fast digestion of waxy maize resulted already in hypertriglyceridemia, possibly due to hepatic neolipogenesis. At the same sampling time, the activity of free amylase was reduced in the intestine of sea bass fed resistant starch, but maltase activity was stimulated in the brush border membranes of enterocytes in the same group, confirming thus the timely digestion of resistant starch. Hepatic mRNA transcripts indicated that glucose metabolism was oriented towards neoglucogenesis by the high-fibre diets, and towards glucose storage by the starchy diets, especially with waxy maize. The diet influenced both faecal and mucosal microbiota, though in a different way, likely due to the interaction with the host. Lupin meal seemed potentially interesting as a source of prebiotic polysaccharides, by modifying the balance between Vibrio spp. and Clostridium sp. Both forms of starch were also partly metabolized by microbiota, resulting in an increased concentration of acetate in the faeces.
\end{abstract}




\section{Highlights}

The diet of sea bass juveniles can contain at least $25 \%$ starch - The metabolic response to dietary carbohydrates is flexible More than $30 \%$ lupin meal can be introduced, with possible prebiotic effect - Intestinal microbiota is influenced by the diet Microbes contribute to starch digestion, as showed by acetate production in faeces

\section{Abbreviations}

ANOSIM, ANalysis Of Similarities;

GK, GlucoKinase;

GLUT2, Glucose Transporter 2;

HPLC, High-Performance Liquid Chromatography;

LC-MS, Liquid Chromatography-Mass Spectrometry;

OTU, Operational Taxonomic Unit;

PEPCK, PhosphoEnolPyruvate CarboxyKinase;

RT-PCR-DGGE, Denaturing Gradient Gel Electrophoresis of products obtained after Polymerase Chain Reaction of RNA templates transformed in complementary DNA by Reverse Transcription;

SCFA, Short Chain Fatty Acids;

SGR, Specific Growth Rate;

SIMPER, SIMilarity PERcentage

Keywords : Digestive enzymes ; glucose metabolism ; intestinal microbiota ; viscerosomatic index ; gene expression ; metabolite analyses ; vegetable feedstuffs

\section{Introduction}

One of the main challenges for sustainably developing aquaculture is to increase feed supply without jeopardizing natural resources. Fish can adapt to feed changes with specific limitations, particularly due to glucose metabolism in carnivorous fishes (Polakof et al., 2012a). European sea bass can regulate relatively high levels of plasmatic glucose within $24 \mathrm{~h}$ (Peres et al., 1999), and the species may use efficiently up to $20 \%$ digestible carbohydrates (Enes et al., 2011). Vegetal sources contain digestible 
polysaccharides mainly in the form of starches with variable proportions of amylopectin and amylose. Amylopectin is a highly branched polymer, which is quickly digested and increases glycaemia (Hu et al., 2004). In sea bass, Enes et al. (2006) showed a higher digestibility of waxy maize starch (99\% amylopectin) compared to normal starch $(72 \%$ amylopectin). However, growth performance and feed efficiency were not affected in this experiment. The digestion kinetics of starch depend on the proportion of amylose a relatively linear polymer, besides other functional properties, such as swelling, viscosity, and pasting parameters (Blazek and Copeland, 2010). A positive effect of starch with high amylose content $(70 \%)$ was demonstrated on the glycaemic regulation in sunshine bass by Rawles and Lochman (2003). Such resistant starch has not been tested yet in sea bass, but the partial substitution of fish meal and gelatinized corn starch by amylose-rich pea seed meal improved protein utilization efficiency and hepatosomatic index, when the diet included 20-30\% of this ingredient (dry matter basis, Gouveia and Davies, 2000). Other pea seeds were tested as alternative starch sources in the diet of sea bass, with positive effects on digestion and glycaemia (Adamidou et al., 2009). Resistant starch affects faecal microbiota in human, by decreasing generally the relative abundance of Firmicutes, while increasing the proportion of Actinobacteria, Bifidobacteriaceae in particular (Martinez et al., 2010). Sugita et al. (1997) suggested that the production of amylase by intestinal bacteria contributed to starch digestion in freshwater fish, and likely also in species living in coastal water (Sugita et al., 1996). The intestinal fermentation of carbohydrates was demonstrated in several species, including sea bass (Leenhouwers et al., 2008). The implication of intestinal microbiota on carbohydrate utilization in fish has been scarcely considered so far, in spite of the numerous studies reviewed by Stone (2003). Such host- 
microbes interaction could help to solve unanswered questions. For example, Enes et al. (2006) noted the protein-sparing effect of carbohydrates that was obtained with starch, either rich in amylose or not, though the starchy diets caused little apparent effect on glucose metabolism in the liver of sea bass. These authors hypothesized alternative muscular or excretory pathways, but possible interaction with intestinal bacteria should also be considered. The present work attempted to reconsider the effects of the form of dietary starch (1) on starch digestion in sea bass and the consequences on postprandial glycaemia and hepatic glycogen storage, and (2) on the concomitant changes in intestinal microbiota. Vegetable protein sources contain also non-starch polysaccharides that are not directly digestible by fish, but that may benefit the host through bacterial interactions (Sinha et al., 2011). For example, lupin meal, affected intestinal microbiota in gilthead sea bream (Silva et al., 2011). In the present experiment, the effects of the starchy diets were compared to those of two other diets containing either cellulose as the only carbohydrate source (control group), or also the other non-starch polysaccharides brought by lupin meal.

\section{Material and methods}

\subsection{Experimental design, rearing conditions and diets}

A total of 370 sea bass juveniles were tagged and distributed evenly in twenty-four 100L tanks in a flow-through system. The initial mean weight was $40.6 \pm 0.3 \mathrm{~g}$, without significant difference between tanks. The water temperature was maintained at $23^{\circ} \mathrm{C}$, and the experiment lasted 2 months.

The experiment was designed based on the results obtained by Enes et al. (2006). Four

diets were prepared with similar supply of protein $\left(420-430 \mathrm{~g} \mathrm{~kg}^{-1}\right.$; Table 1$)$. The effects 
of three different carbohydrate sources were studied in comparison with a control diet containing fish meal and fish hydrolysate as only protein sources, and cellulose as single carbohydrate additive (FM). Two forms of starch were compared $\left(250 \mathrm{~g} \mathrm{~kg}^{-1}\right)$, either highly digestible (waxy maize WM, containing 99\% amylopectin), or slowly digestible (amylomaize AM, resistant starch containing 70\% amylose and 30\% amylopectin). The two starchy diets were compared to diet FM, and to a fourth diet with lupin meal that is rich in non-starch polysaccharides (LPM). The four diets were allotted to 6 replicates each (24 tanks in total). The diets were pelletised at mild temperature with a twin screw extruder (BC 45, Clextral, France) to avoid starch degradation (Liu et al., 2010; extrusion temperatures: $67^{\circ} \mathrm{C}, 58^{\circ} \mathrm{C}, 56^{\circ} \mathrm{C}$, and $74^{\circ} \mathrm{C}$ for diets $\mathrm{FM}, \mathrm{WM}, \mathrm{AM}$, and LPM, respectively). The fish were fed $12 \mathrm{~h}$ a day under artificial daylight exposure with automatic continuous feeders. Before starting the experiment, the fish were adapted to the rearing conditions for two months, during which they were fed a commercial diet (Neo Grower Extra Marin; 43\% protein, 20\% fat; Le Gouessant Aquaculture, Lamballe, France).

\subsection{Sampling and analytical methods}

Eight individuals were sampled per tank at the start of the experiment, after feeding the commercial diet. In the morning of the sampling day, six hours before sampling, the fish were hand-fed to satiation. Then in the afternoon, under anaesthesia, faeces were gently harvested by abdominal stripping, and immediately frozen for metabolite analyses. Fish were sampled during two consecutive afternoons, six hours after hand-feeding, which corresponded to the optimal time for postprandial faecal production. After these two sampling days, the commercial feed was replaced by the experimental diets. By the end of the experiment, 56 days after the first sampling, faeces were collected again from 
four of the eight individuals initially sampled per tank. The faeces were collected in the same conditions as those used at the beginning of the experiment, but after feeding the experimental diets. The individual faecal samples were divided in two collection tubes. One tube was immediately frozen, as intended to analyse short-chain fatty acids (SCFA) by gas chromatography (Jouany, 1982; Zhao et al., 2006) and other metabolites by liquid chromatography-mass spectrometry (LC-MS; Hansen et al., 2013; Supplementary Material S4). The second tube contained Extract-All (Eurobio) for RNA extraction and RT-PCR-DGGE with the method of Lamari et al. (2013). The fish were fed the experimental diets until the day of final sampling. At the end of the experiment, the same four individuals per tank were euthanized. This final sampling lasted 3 days, in a way to collect the blood samples for glycaemia and triglyceridemia measurement $7 \pm 1$ hours after the last meal in the eight tanks that were treated on each of the three days ( 2 tanks $\operatorname{diet}^{-1}$ day $^{-1}$; Ducasse-Cabanot et al., 2007). At the same time, the fish were dissected, and the samples were chilled on ice. The intestine was washed out to empty the remaining contents before sampling. The proximal intestine was reserved for activity assays of digestive enzymes: free $\alpha$-amylase (Metais and Bieth, 1968) and maltase in the brush border membrane of enterocytes (Ducasse-Cabanot et al., 2007). The liver was separated for RNA extraction to compare the expression of functional genomic markers: GK, PEPCK, and GLUT2 (Polakof et al., 2012b). Gut mucosa and associated microbiota were squeezed out from the distal intestine with metallic spatula, and collected with sterile tweezers for RNA extraction and RT-PCR-DGGE. The method allowed to discriminate the bacterial phyloptypes after the partial sequences of $16 \mathrm{~S}$ ribosomal RNA, but these sequences could not be systematically read. When 
feasible, some bands were extracted from the DGGE gels for bacterial sequencing (Lamari et al., 2013).

\subsection{Statistics}

Body analyses and faecal SCFA production were compared by ANOVA or KruskalWallis test, depending on normality and homoscedasticity. Post-hoc tests were used for multiple comparisons between dietary groups: Tukey after ANOVA for growth, somatic indices, and acetate production; Student-Newman-Keuls after ANOVA for plasmatic and enzymatic analyses, and after Kruskal-Wallis. The transcript levels of marker genes, and the bacterial community profiles were analysed with REST and PAST softwares, respectively (Ducasse-Cabanot et al., 2007; Lamari et al., 2013). The dissimilarities between the bacterial profiles of the dietary groups were evaluated with Bray-Curtis indices compared by ANOSIM and SIMPER (Clarke, 1993).

\section{Results}

\subsection{Growth and somatic indices}

There was no significant difference between the final mean weights and mean individual specific growth rates (SGR) of the dietary groups (Table 2). However, the non-significantly higher mean weights in Groups LPM and AM were explained by higher viscerosomatic indices in both groups compared to WM and FM. The increase in visceral mass observed in the three experimental diets compared to the control FM was not distributed in the same way. The diet with resistant starch (AM) caused the highest increase in liver mass, followed by the amylopectin-rich diet (WM), and both groups were significantly different from Groups LPM and FM, whose hepathosomatic indices 
were similar. The significant difference observed between the viscerosomatic indices of these last two groups was likely due to an increase of perivisceral fat tissue with the diet containing lupin meal (LPM).

\subsection{Postprandial glycaemia, triglyceridemia, and enzyme activities in the intestine}

Glycaemia was higher $7 \pm 1 \mathrm{~h}$ after the last meal in the group fed resistant starch (AM) compared to the other dietary groups (Table 3). This postprandial timing for sampling was likely too late to observe hyperglycaemia in Group WM, which was characterized however by a higher triglyceridemia.

At the same time, the activity of amylase was lower in the intestine of fish fed resistant starch (AM) compared to the other dietary groups, while higher activity of maltase was observed in the brush border membrane of the enterocytes in the same group compared to the others (Table 3).

\subsection{Hepatic gene expressions for key markers of glucose metabolism and transport}

Glucokinase (GK) is the enzyme that phosphorylates glucose to glucose-6-phosphate, the first limiting step of glucose storage in the liver. The amylopectin-rich diet WM increased significantly the level of expression of the corresponding gene, compared to the control group FM (Fig. 1). This stimulation was less marked with the group fed resistant starch, which was significantly different only from Group LPM in this regard. Conversely, the gene coding for phosphoenolpyruvate carboxykinase (PEPCK) was repressed in the two groups fed starchy diets, which were both significantly different 
from the control with this marker. This enzyme converts oxaloacetate into phosphoenolpyruvate, the first step of gluconeogenesis in the liver, and decreases when the animals are fed carbohydrates. GLUT2 is a bidirectional glucose transporter that is required in liver cells to uptake or to secrete glucose for storage or production, respectively. The expression of the corresponding gene was not significantly different between diets.

\subsection{Microbial communities at the end of the experiment}

By the end of the two months of feeding the experimental diets, the mucosal and faecal communities were significantly affected by the diet. The comparison of Bray-Curtis similarity by ANOSIM indicated that the bacterial profiles were dissimilar between the samples from every dietary group, except between the faeces of Groups WM and FM (Table 4). In the faecal samples, the SIMPER overall average dissimilarity between all the diets was higher than in the mucosal samples (55.9 and 51.8\%, respectively). This was due to the faecal samples of Group LPM that appeared as the most dissimilar from the others.

The main OTU contributing to dissimilarity between dietary groups among mucosal samples was identified as Vibrio sp. BJ (Table 5), which was abundant with the starchy diets, and particularly less abundant with diet LPM, while an unidentified OTU was abundant with the non-starch diets (8\%, Supplementary Table S1). Clostridium sp. DQ was abundant with diets AM and LPM (8\%), and the most abundant OTU corresponded to Enterobacteriaceae DE, particularly with LPM (11\%).

In the faecal samples, the main OTUs contributing to dissimilarity between dietary groups were distributed quite differently from what was observed in the mucosal 
samples. the most abundant faecal OTU corresponded still to Enterobacteriaceae DE, which was present at the same relative level as in mucus in Group LPM (11\%), while the abundance of this OTU was higher in the other dietary groups, compared to the mucosal data, especially with the starchy diets (Supplementary Table S2). The other dominant OTUs in Groups AM and FM were not identified. Clostridium sp. DQ was much less abundant in the faeces from Group AM, compared to the mucosal samples, while this OTU was abundant in both compartments with diet LPM. Another difference between Groups AM and LPM was about the abundance of Methylocella sp. DR, which was relatively high in the faecal samples from Group LPM, and low in those from Group AM, whereas the reverse trend was observed in mucus. In faeces, there was no detection of Vibrio sp. BJ, which was especially abundant in the mucosal samples with the starchy diets. A closely related OTU, Vibrio sp. DP, was detected instead, and particularly abundant in Group LPM, whereas another OTU, Vibrio sp. AY, was more abundant in the starchy diets. Two other OTUs were also identified: Brevinema sp. DZ (3\% with diet AM), and Saccharopolyspora sp. BI (3\% with diet LPM). In Group FM, the OTU distribution of the faecal samples was evener and more equitable than in the groups fed the starchy diets (Supplementary Table S3).

\subsection{Short chain fatty acids and other faecal metabolites}

SCFA were determined in faecal samples collected from all diet groups one week before the end of the experiment. Acetic acid was the only SCFA detected with the method applied. The highest concentrations were detected in AM and WM, indicating higher fermentation activities in these groups (Table 6). In Group AM, the untargeted metabolite analysis by LC-MS revealed a high diversity of faecal metabolites, which 
differed from those of Groups FM and LPM (Supplementary material S4). The annotation of metabolites revealed that Group LPM contained peptides that did not appear in the other groups.

\section{Discussion}

Pereira and Oliva-Teles (2004) did not find any influence of dietary lupin meal on somatic indices of gilthead sea bream, at variance with the present study on sea bass. In another experiment, lupin meal depressed maltase activity in gilthead sea bream enterocytes (Silva et al., 2010), contrary to what was presently observed in sea bass. That may suggest some discrepancy between the dietary influences of lupin meal on the two species, which differed in their response to the inclusion of other plant raw materials (Nikolopoulou, 2009). The evacuation rate from stomach is slower in sea bass compared to sea bream, with higher hydratation level, and lower $\mathrm{pH}$ (Nikolopoulou et al., 2011). That may result in further hydrolysis of the digestible polysaccharides brought by lupin meal in sea bass compared to sea bream, and then in higher maltase activity in the enterocytes. This better digestive efficiency of lupin meal in sea bass did not benefit to growth, or to hepatic neoglycogenesis, but it increased likely the perivisceral mass. Another vegetable diet with mixed protein sources caused an increase of mesenteric fat in rainbow trout (de Francesco et al., 2004), which may corroborate the effect of lupin meal that was deduced from the viscerosomatic index of sea bass. The reason for such fat deposition is not clear, but possibly related to endocrinal regulation.

Enes et al. (2006) noted that diets with normal or waxy maize starch did not affect growth in sea bass. The viscerosomatic index was not significantly affected by the diets 
in the experiment of Enes et al. (2006), but starch was incorporated at 10-20\% in the diet, instead of $25 \%$ in the present experiment. In the experiment of Enes et al. (2006), the significant differences between the hepatosomatic indices of the dietary groups did not comply with the form and amount of starch supplied, but the highest index corresponded to the group fed $20 \%$ normal starch (72\% amylopectin, $28 \%$ amylose). In the present experiment, the $25 \%$ of starch supply increased the liver mass, especially with resistant starch. Surprisingly, the hepatic reserve storage seemed particularly stimulated with a high amount of amylose in sea bass, whereas the hepatosomatic index increased in sunshine bass with the digestibility of dietary carbohydrates (Rawles and Lochman, 2003). Other experiments on European sea bass indicated that somatic indices correlated generally with the amount of gelatinized starch (Peres and OlivaTeles, 2002; Moreira et al., 2008; Enes et al., 2010), unlike with raw starch (Dias et al., 1998; Peres and Oliva-Teles, 2002). However, such indices are too rough to reflect accurately the utilization of carbohydrates.

The postprandial glycaemia kinetics seemed to differ between sea bass and sunshine bass, in which blood glucose clearance was slower with amylopectin than with amylose (Rawles and Lochman, 2003). Enes et al. (2006) did not detect significant differences in glycaemia $6 \mathrm{~h}$ after the last meal, whether sea bass were fed diets containing 10 or $20 \%$ of either waxy maize or normal starch. In the present experiment with $25 \%$ starch in the diet, blood glucose was more elevated at $7 \mathrm{~h}$ with resistant starch compared to the group fed waxy maize, suggesting some delay in the peak of postprandial glycaemia with high supply of slow sugar. Peres et al. (1999) argued an important role of plasmatic triacylglycerides in glucose regulation. It is likely that the high postprandial 
triglyceridemia observed at $7 \mathrm{~h}$ with waxy maize corresponded to subsequent lipogenesis in the liver after early plasmatic glucose clearance.

The postprandial activities of digestive enzymes in the intestine, and the concomitant level of plasmatic glucose, confirmed the difference in hydrolysis velocity between the two forms of dietary starch. Amylolysis requires the adsorption of amylase in the crystalline structure of amylopectin (Warren et al., 2013). Hamid et al. (2011) noted that the specific activity of amylase was higher with A-type starch than with C-type, which is intermediary between A-type and B-type starches. Waxy maize is classified as type A, whereas amylopectin is of type B in amylomaize (Jane, 2004). It seems that the adsorption of amylase was slower on amylomaize that was harder to hydrolyse than the almost pure matrix of A-type amylopectin in waxy maize. That resulted in a lower level of free amylase $7 \mathrm{~h}$ after the last meal in the intestine of fish fed resistant starch, compared to the other diets. This slow release of maltose stimulated a higher activity of maltase in the enterocytes, resulting in a higher level of glucose in the plasma. In the meanwhile, the easy hydrolysis of waxy maize seemed already completed in Group WM, and the enzymatic activities and glycaemia rejoined the baseline levels observed with the two groups fed without starch.

The GK mRNA level is a highly specific marker of hepatic glucose phosphorylation in fish (Enes et al., 2009). The up-regulation of gene GK confirmed the glycaemic surge in the group fed waxy maize, compared to the control without starch. A stimulation of hepatic glucokinase activity was already observed by Enes et al. (2006), whether sea bass were fed way maize or normal starch. Interestingly, the trend of GK gene overexpression was not significant in the group fed resistant starch, suggesting further a self-regulation of glucose release due to slow digestion of amylomaize. In fish, PEPCK 
activity is highly specific to gluconeogenic tissues. The nutritional regulation of this activity was generally not evidenced in fish liver, due to the prevalence of the mitochondrial activity that is not dependent on the nutritional status, unlike the cytosolic activity (Enes et al., 2009). In sea bass however, PEPCK gene expression was downregulated in the two groups fed starchy diets compared to the control, confirming thus an efficient response to dietary carbohydrates at a metabolic level. GLUT2 is involved in glucose homeostasis by facilitating the transport across the membrane of hepatocytes, and the gene needs to be highly expressed irrespective of the nutritional status. In agreement with Enes et al. (2009), there was no significant difference between the expression levels of GLUT2 gene in the present experiment.

The intestinal microbial community may also be involved in the differences observed in the host, since it was significantly modulated by feed composition. It should be kept in mind that RT-PCR-DGGE was used in this experiment to focus on the active part of microbiota by comparing the abundances of $16 \mathrm{~S}$ ribosomal RNA. The difference observed between DNA- and RNA-based analyses has been documented in fish microbiota (Navarrete et al., 2012; Lamari et al., 2013). In spite of a core intestinal microbiota that may resist dietary change in rainbow trout (Wong et al., 2013), there is growing evidence that another fraction of the bacterial community does depend on feed components in the intestine of trout (Heikkinen et al., 2006; Merrifield et al., 2009; Mansfield et al., 2010; Desai et al., 2012; Navarrete et al., 2012) and other fish (Ring $\varnothing$ et al., 2006; Silva et al., 2011). In the faecal samples of the present experiment, the lupin meal caused the maximum dissimilarity in bacterial profiles, compared to the control group. This dissimilarity was already noted in the intestinal contents of gilthead sea bream by Silva et al. (2011). Lupin is generally rich in $\alpha$-galactosides, which can 
influence faecal microbiota, possibly repressing some Vibrionaceae in gilthead sea bream (Silva et al., 2011). In the present experiment the dominant Vibrio sp. was different in the faeces of sea bass fed the different diets, while Clostridium sp. was promoted with lupin. Faecal microbiota are quite different in sea bass and man, and they seem differently affected by lupin fibre. Smith et al. (2006) noted the bifidogenic effect of lupin kernel fibre in human stools, whereas one group of Clostridium sp. was repressed. The mucus-associated bacteria were affected by the diet, but likely also in interaction with the host. The dominant Vibrio sp. in mucus was different from those observed in faeces, and particularly repressed in the group fed lupin. This meal seems an interesting feed component, as a source of non-starch polysaccharides, possibly limiting opportunistic bacteria such as Vibrionaceae. Starch, particularly amylopectin, should be added carefully in view of the possible stimulation of opportunists. However in the present experiment, the faecal community of the group fed waxy maize was not significantly dissimilar from that of the control group, whereas resistant starch and lupin meal affected clearly the bacterial profiles. The four groups showed dissimilar mucosal communities, and the fast digestion of waxy maize by sea bass may indirectly influence the bacterial profile at the mucosal interface. Many intestinal bacteria that produce amylase may interfere on starch digestion, including Enterobacteriaceae and Vibrionaceae isolated in marine fish (Sugita et al., 1996), Clostridium sp. in freshwater fish (Sugita et al., 1997), and Saccharopolyspora sp. A9 in marine sediment (Chakraborty et al., 2011).

Acetate is by far the most abundant short chain fatty acid that is produced in the intestine of mammals fed resistant starch and non-starch polysaccharides (Topping and Clifton, 2001). Acetate is also the predominant SCFA produced in fish intestine (Smith 
et al., 1996; Clements, 1997). It should be kept in mind that butyrate and other SCFA are quickly metabolised by enterocytes as energy source, and that such beneficial compounds may be efficient, even remaining below the detection threshold. The starchy diets gave the highest concentration of acetate in sea bass faeces, suggesting that not only amylomaize, but also waxy maize, were partly metabolized by microbiota in fish intestine. Clements et al. (1994) stressed that plasmatic acetate can be produced either from intestinal fermentation, or from endogenous hydrolysis of acetyl CoA. However, the intestinal excretion of endogenous acetate is unlikely, and a fermentative origin can be assumed for the greatest part of faecal acetate. A decrease of the intestinal $\mathrm{pH}$ due to SCFA production in herbivorous fish was hypothetized by Clements (1997), but such effect was likely negligible in sea bass, due to the low concentration of faecal acetate. It is clear that the diet influenced intestinal microbiota, but the impact of these changes on the host remains to be evaluated. Untargeted metabolite analysis is a new approach that may contribute to the understanding of the function of the intestinal microbiota and the interactions with the host (Zheng et al., 2011; Matsumoto et al., 2012). Analyses of faecal metabolites by LC-MS with "time-of-flight" (TOF) detection confirmed the differences observed between dietary groups (Supplementary material S4). Resistant starch produced the highest diversity of metabolites, possibly due to the wide distribution of amylases among bacteria (Pandey et al., 2000). The metabolite profile obtained with lupin meal appeared less dissimilar from that of the control group, but the influence of the vegetable source protein on the bacterial profile in faeces suggests that competent bacteria were selectively stimulated to produce a limited number of digestion products. In particular, lupin meal induced the production of peptides that were not 
found in the other groups, likely due to the difference in dietary proteins, but the possible interaction with intestinal microbiota remained unclear.

\section{Conclusion}

Though sea bass is strictly carnivorous in the wild, this experiment confirmed that the species can be fed large amount of plant carbohydrates. Its diet can contain at least $25 \%$ starch without detrimental effect, and the faecal production of acetate suggested a bacterial contribution to the digestion process. As proposed by Karasov et al. (2011), the functional flexibility of the microbiome play likely an important role in the digestive adaptability of fish, but that remains to be further investigated.

\section{Acknowledgements}

This work was carried out with financial support from the Commission of the European Communities, specific RTD programme of Framework Programme 7, PROMICROBE (GA 227197).

\section{References}

Adamidou, S., Nengas, I., Alexis, M., Foundoulaki, E., Nikolopoulou, D., Campbell, P., Karacostas, I., Rigos, G., Bell, G.J., Jauncey, K., 2009. Apparent nutrient digestibility and gastrointestinal evacuation time in European seabass (Dicentrarchus labrax) fed diets containing different levels of legumes. Aquaculture 289, 106-112.

Blazek, J., Copeland, L., 2010. Amylolysis of wheat starches. I. Digestion kinetics of starches with varying functional properties. J. Cereal Sci. 51, 265-270. 
Chakraborty, S., Khopade, A., Biao, R., Jian, W., Liu, X.Y., Mahadik, K., Chopade, B., Zhang, L.X., Kokare, C., 2011. Characterization and stability studies on surfactant, detergent and oxidant stable $\alpha$-amylase from marine haloalkaliphilic Saccharopolyspora sp. A9. J. Mol. Catal. 68B, 52-58.

Clarke, K.R., 1993. Non-parametric multivariate analysis of changes in community structure. Aust. J. Ecol. 18, 117-143.

Clements, K.D., 1997. Fermentation and gastrointestinal microorganisms in fishes, in: Mackie, R.I., White, B.A. (Eds.), Gastrointestinal Microbiology, Vol. 1, Gastrointestinal Ecosystems and Fermentations, Chapman \& Hall, New York, pp. 156-198.

Clements, K.D., Gleeson, V.P., Slaytor, M., 1994. Short-chain fatty acid metabolism in temperate marine herbivorous fish. J. Comp. Physiol. 164B, 372-377.

de Francesco, M., Parisi, G., Medale, F., Lupi, P., Kaushik, S.J., Poli, B.M., 2004. Effect of long-term feeding with a plant protein mixture based diet on growth and body/fillet quality traits of large rainbow trout (Oncorhynchus mykiss). Aquaculture 236, 413-429.

Desai, A.R., Links, M.G., Collins, S.A., Mansfield, G.S., Drew, M.D., Van Kessel, A.G., Hill, J.E., 2012. Effects of plant-based diets on the distal gut microbiome of rainbow trout (Oncorhynchus mykiss). Aquaculture 350, 134-142. 
Dias, J., Alvarez, M.J., Diez, A., Arzel, J., Corraze, G., Bautista, J.M., Kaushik, S.J., 1998. Regulation of hepatic lipogenesis by dietary protein/energy in juvenile European seabass (Dicentrarchus labrax). Aquaculture 161, 169-186.

Ducasse-Cabanot, S., Zambonino-Infante, J., Richard, N., Medale, F., Corraze, G., Mambrini, M., Robin, J., Cahu, C., Kaushik, S., Panserat, S., 2007. Reduced lipid intake leads to changes in digestive enzymes in the intestine but has minor effects on key enzymes of hepatic intermediary metabolism in rainbow trout (Oncorhynchus mykiss). Animal 1, 1272-1282.

Enes, P., Panserat, S., Kaushik, S., Oliva-Teles, A., 2006. Effect of normal and waxy maize starch on growth, food utilization and hepatic glucose metabolism in European sea bass (Dicentrarchus labrax) juveniles. Comp. Biochem. Physiol. 143A, 89-96.

Enes, P., Panserat, S., Kaushik, S., Oliva-Teles, A., 2009. Nutritional regulation of hepatic glucose metabolism in fish. Fish Physiol. Biochem. 35, 519-539.

Enes, P., Sanchez-Gurmaches, J., Navarro, I., Gutiérrez, J., Oliva-Teles, A., 2010. Role of insulin and IGF-I on the regulation of glucose metabolism in European sea bass (Dicentrarchus labrax) fed with different dietary carbohydrate levels. Comp. Biochem. Physiol. 157A, 346-353. 
Enes, P., Panserat, S., Kaushik, S., Oliva-Teles, A., 2011. Dietary Carbohydrate Utilization by European Sea Bass (Dicentrarchus labrax L.) and Gilthead Sea Bream (Sparus aurata L.) Juveniles. Rev. Fish. Sci. 19, 201-215.

Gouveia, A., Davies, S.J., 2000. Inclusion of an extruded dehulled pea seed meal in diets for juvenile European sea bass (Dicentrarchus labrax). Aquaculture 182, 183-193.

Hamid, N.K.A., Mahayat, M., Hashim, R., 2011. Utilization of different carbohydrate sources and starch forms by bagrid catfish (Mystus nemurus) (Cuv \& Val). Aquacult. Nutr. 17, e10-e18.

Hansen, B.H., Degnes, K., Øverjordet, I.B., Altin, D., Størseth, T.R., 2013. Metabolic fingerprinting of arctic copepods Calanus finmarchicus, Calanus glacialis and Calanus hyperboreus. Polar Biol. 36, 1577-1586.

Heikkinen, J., Vielma, J., Kemilainen, O., Tiirola, M., Eskelinen, P., Kiuru, T., NaviaPaldanius, D., von Wright, A., 2006. Effects of soybean meal based diet on growth performance, gut histopathology and intestinal microbiota of juvenile rainbow trout (Oncorhynchus mykiss). Aquaculture 261, 259-268.

Hu, P., Zhao, H., Duan, Z., Linlin, Z., Wu, D., 2004. Starch digestibility and the estimated glycemic score of different types of rice differing in amylose contents. J. Cereal Sci. 40, 231-237. 
Jane, J., 2004. Starch: structure and properties, in: Tomasik, P. (Ed.), Chemical and Functional Properties of Food Saccharides. CRC Press LLC, Boca Raton, Florida, pp. 90-110.

Jouany, J.P., 1982. Volatile fatty acid and alcohol determination in digestive contents, silage juices, bacterial cultures and anaerobic fermentor contents. Sci. Aliment. 2, 131144.

Karasov, W.H., del Rio, C.M., Caviedes-Vidal, E., 2011. Ecological physiology of diet and digestive systems. Ann. Rev. of Physiol. 73, 69-93.

Lamari, F., Castex, M., Larcher, T., Ledevin, M., Mazurais, D., Bakhrouf, A., Gatesoupe, F.J., 2013. Comparison of the effects of the dietary addition of two lactic acid bacteria on the development and conformation of sea bass larvae, Dicentrarchus labrax, and the influence on associated microbiota. Aquaculture 376, 137-145.

Leenhouwers, J.I., Pellikaan, W.F., Huizing, H.F.A., Coolen, R.O.M., Verreth, J.A.J., Schrama, J.W., 2008. Fermentability of carbohydrates in an in vitro batch culture method using inocula from Nile tilapia (Oreochromis niloticus) and European sea bass (Dicentrarchus labrax). Aquacult. Nutr. 14, 523-532.

Liu, W.C., Halley, P.J., Gilbert, R.G., 2010. Mechanism of degradation of starch, a highly branched polymer, during extrusion. Macromolecules 43, 2855-2864 
Mansfield, G.S., Desai, A.R., Nilson, S.A., Van Kessel, A.G., Drew, M.D., Hill, J.E., 2010. Characterization of rainbow trout (Oncorhynchus mykiss) intestinal microbiota and inflammatory marker gene expression in a recirculating aquaculture system. Aquaculture 307, 95-104.

Martinez, I., Kim, J., Duffy, P.R., Schlegel, V.L., Walter, J., 2010. Resistant starches types 2 and 4 have differential effects on the composition of the fecal microbiota in human subjects. PLoS ONE 5, 11pp., doi:10.1371/journal.pone.0015046.

Matsumoto, M., Kibe, R., Ooga, T., Aiba, Y., Kurihara, S., Sawaki, E., Koga, Y., Benno, Y., 2012. Impact of intestinal microbiota on intestinal luminal metabolome. Sci. Rep. 2, 10 pp., doi:10.1038/srep00233.

Merrifield, D.L., Dimitroglou, A., Bradley, G., Baker, R.T.M., Davies, S.J., 2009. Soybean meal alters autochthonous microbial populations, microvilli morphology and compromises intestinal enterocyte integrity of rainbow trout, Oncorhynchus mykiss (Walbaum). J. Fish Dis. 32, 755-766.

Metais, P., Bieth, J., 1968. Détermination de l' $\alpha$-amylase par une microtechnique. Ann. Biol. Clin. 26, 133-142.

Moreira, I.S., Peres, H., Couto, A., Enes, P., Oliva-Teles, A., 2008. Temperature and dietary carbohydrate level effects on performance and metabolic utilisation of diets in European sea bass (Dicentrarchus labrax) juveniles. Aquaculture 274, 153-160. 
Navarrete, P., Magne, F., Araneda, C., Fuentes, P., Barros, L.,Opazo, R., Espejo, R., Romero, J., 2012. PCR-TTGE Analysis of 16S rRNA from rainbow trout (Oncorhynchus mykiss) gut microbiota reveals host-specific communities of active bacteria. PloS ONE 7, 10 pp., doi:10.1371/journal.pone.0031335.

Nikolopoulou, D., 2009. Studies on the composition of legumes and carob seed germ meal and their effect on physiology and biochemistry of digestion of Mediterranean fish species. PhD thesis, University of Thessaly, Department of Biochemistry and Biotechnology, Larissa, Greece, 197 pp.

Nikolopoulou, D., Moutou, K.A., Fountoulaki, E., Venou, B., Adamidou, S., Alexis, M.N., 2011. Patterns of gastric evacuation, digesta characteristics and pH changes along the gastrointestinal tract of gilthead sea bream (Sparus aurata L.) and European sea bass (Dicentrarchus labrax L.). Comp. Biochem. Physiol. 158A, 406-414.

Pandey, A., Nigam, P., Soccol, C.R., Soccol, V.T., Singh, D., Mohan, R., 2000. Advances in microbial amylases. Biotechnol. Appl. Biochem. 31, 135-152.

Pereira, T.G., Oliva-Teles, A., 2004. Evaluation of micronized lupin seed meal as an alternative protein source in diets for gilthead sea bream Sparus aurata L. juveniles. Aquacult. Res. 35, 828-835. 
Peres, H., Oliva-Teles, A., 2002. Utilization of raw and gelatinized starch by European sea bass (Dicentrarchus labrax) juveniles. Aquaculture 205, 287-299.

Peres, H., Gonçalves, P., Oliva-Teles, A., 1999. Glucose tolerance in gilthead seabream (Sparus aurata) and European seabass (Dicentrarchus labrax). Aquaculture 179, 415423.

Polakof, S., Panserat, S., Soengas, J.L., Moon, T.W., 2012a. Glucose metabolism in fish: a review. J. Comp. Physiol. 182B, 1015-1045.

Polakof, S., Skiba-Cassy, S., Kaushik, S., Seiliez, I., Soengas, J.L., Panserat, S., $2012 b$. Glucose and lipid metabolism in the pancreas of rainbow trout is regulated at the molecular level by nutritional status and carbohydrate intake. J. Comp. Physiol. 182B, 507-516.

Rawles, S., Lochmann, R., 2003. Effects of amylopectin/amylose starch ratio on growth, body composition and glycemic response of sunshine bass Morone chrysops $q$ $\times$ M. saxatilis $\widehat{\text { }}$. J. World Aquacult. Soc. 34, 278-288.

Ringø, E., Sperstad, S., Myklebust, R., Refstie, S., Krogdahl, Å., 2006. Characterisation of the microbiota associated with intestine of Atlantic cod (Gadus morhua L.): The effect of fish meal, standard soybean meal and a bioprocessed soybean meal. Aquaculture 261, 829-841. 
Silva, F.C.P., Nicoli, J.R., Zambonino-Infante, J.L., Le Gall, M.M., Kaushik, S., Gatesoupe, F.J., 2010. Influence of partial substitution of dietary fish meal on the activity of digestive enzymes in the intestinal brush border membrane of gilthead sea bream, Sparus aurata and goldfish, Carassius auratus. Aquaculture 306, 233-237.

Silva, F.C.P., Nicoli, J.R., Zambonino, J.L., Kaushik, S., Gatesoupe, F.J., 2011. Influence of the diet on microbial diversity of faecal and gastrointestinal contents in gilthead sea bream (Sparus aurata) and intestinal contents in goldfish (Carassius auratus). FEMS Microbiol. Ecol. 78, 285-296.

Sinha, A.K., Kumar, V., Makkar, H.P.S., De Boeck, G., Becker, K., 2011. Non-starch polysaccharides and their role in fish nutrition - A review. Food Chem. 127, 1409-1426.

Smith, T.B., Wahl, D.H., Mackie, R.I., 1996. Volatile fatty acids and anaerobic fermentation in temperate piscivorous and omnivorous freshwater fish. J. Fish Biol. 48, 829-841.

Smith, S.C., Choy, R., Johnson, S.K., Hall, R.S., Wildeboer-Veloo, A.C.M., Welling, G.W., 2006. Lupin kernel fiber consumption modifies fecal microbiota in healthy men as determined by rRNA gene fluorescent in situ hybridization. Eur. J. Nutr. 45, 335-341.

Stone, D.A.J., 2003. Dietary carbohydrate utilization by fish. Rev. Fish. Sci. 11, 337369. 
Sugita, H., Kawasaki, J., Kumazawa, J., Deguchi, Y., 1996. Production of amylase by the intestinal bacteria of Japanese coastal animals. Lett. Appl. Microbiol. 23, 174-178.

Sugita, H., Kawasaki, J., Deguchi, Y., 1997. Production of amylase by the intestinal microflora in cultured freshwater fish. Lett. Appl. Microbiol. 24, 105-106.

Topping, D.L., Clifton, P.M., 2001. Short-chain fatty acids and human colonic function: Roles of resistant starch and nonstarch polysaccharides. Physiol. Rev. 81, 1031-1064.

Warren, F.J., Butterworth, P.J., Ellis, P.R., 2013. The surface structure of a complex substrate revealed by enzyme kinetics and Freundlich constants for $\alpha$-amylase interaction with the surface of starch. BBA - Gen. Subjects 1830, 3095-3101.

Wong, S., Waldrop, T., Summerfelt, S., Davidson, J., Barrows, F., Kenney, P.B., Welch, T., Wiens, G.D., Snekvik, K., Rawls, J.F., Good, C., 2013. Aquacultured rainbow trout (Oncorhynchus mykiss) possess a large core intestinal microbiota that is resistant to variation in diet and rearing density. Appl. Environ. Microbiol. 79, 49744984.

Zhao, G.H., Nyman, M., Jonsson, J.A., 2006. Rapid determination of short-chain fatty acids in colonic contents and faeces of humans and rats by acidified water-extraction and direct-injection gas chromatography. Biomed. Chromatogr. 20, 674-682. 
Zheng, X., Xie, G., Zhao, A., Zhao, L., Yao, C., Chiu, N.H., Zhou, Z., Bao, Y., Jia, W., Nicholson, J.K., Jia, W., 2011. The footprints of gut microbial-mammalian cometabolism. J. Proteome Res. 10, 5512-5522.

\section{Figure caption}

Fig. 1. Relative expression levels of the genes coding for glucokinase (GK),

Phosphoenolpyruvate carboxykinase (PEPCK), and Glucose Transporter GLUT2 in the liver of sea bass fed the four diets, $7 \pm 1 \mathrm{~h}$ after the last meal. The standard deviation of mean level is represented as a vertical segment, and letters a, b and c indicate the significant differences between groups. 

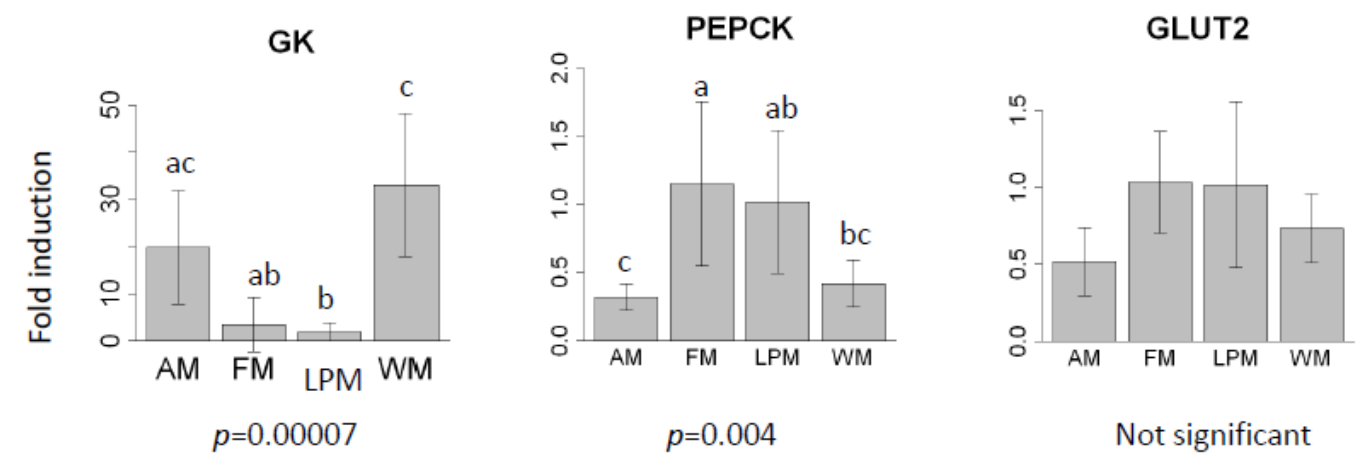

Figure 1 
Table 1

Composition of the experimental diets.

\begin{tabular}{|c|c|c|c|c|}
\hline & FM & LPM & AM & WM \\
\hline \multicolumn{5}{|c|}{ Ingredients ( $\mathrm{g} \mathrm{kg}^{-1}$ ) } \\
\hline Fish meal & 539.3 & 350.0 & 539.3 & 539.3 \\
\hline Fish soluble & 80.0 & & 80.0 & 80.0 \\
\hline Soft white lupin & 0.0 & & 0.0 & 0.0 \\
\hline Fish oil & 110.7 & 116.1 & 110.7 & 110.7 \\
\hline Cellulose & & 125.5 & 0.0 & 0.0 \\
\hline Amylomaize & 0.0 & 0.0 & 250.0 & 0.0 \\
\hline Waxy maize & 0.0 & 0.0 & 0.0 & 250.0 \\
\hline Mineral premix & 10.0 & 10.0 & 10.0 & 10.0 \\
\hline Vitamin premix & 10.0 & 10.0 & 10.0 & 10.0 \\
\hline
\end{tabular}




\section{Table 2}

Growth and somatic indices of the four dietary groups at the end of the experiment $( \pm$ standard error). Superscripts a, b and c indicate the significant differences between diets (post-hoc test: Tukey after ANOVA; Student-Newman-Keuls after KW: Kruskal-Wallis; n.s.: not significant).

\begin{tabular}{lccccc}
\hline & FM & LPM & AM & WM & Comparison \\
& & & & \\
\hline Initial mean weight (g) & $40.5 \pm 0.7$ & $40.3 \pm 0.6$ & $40.8 \pm 0.8$ & $41.0 \pm 0.7$ & KW (n.s.) \\
& & & & \\
Final mean weight (g) & $90.4 \pm 3.3$ & $97.9 \pm 2.6$ & $96.2 \pm 3.4$ & $93.3 \pm 2.8$ & ANOVA (n.s.) \\
Individual SGR & $0.55 \pm 0.03$ & $0.61 \pm 0.02$ & $0.61 \pm 0.02$ & $0.58 \pm 0.02$ & KW (n.s.) \\
Viscerosomatic index & $9.3^{\mathrm{c}} \pm 0.3$ & $11.1^{\mathrm{a}} \pm 0.4$ & $11.3^{\mathrm{a}} \pm 0.3$ & $10.4^{\mathrm{b}} \pm 0.4$ & $\mathrm{KW}(p<0.001)$ \\
\hline Hepathosomatic index & $1.20^{\mathrm{c}} \pm 0.07$ & $1.36^{\mathrm{c}} \pm 0.07$ & $3.34^{\mathrm{a}} \pm 0.112 .34^{\mathrm{b}} \pm 0.10$ & ANOVA ( $p<0.001)$ \\
\hline
\end{tabular}




\section{Table 3}

Mean plasmatic concentrations of glucose and triglycerides and specific enzymatic activities in the intestine ( $\pm S D), 7 \pm 1 \mathrm{~h}$ after the last meal of sea bass fed one of the four diets. Letters a and $\mathrm{b}$ indicate the significant differences between diets (post-hoc test: Student-Newman-Keuls after ANOVA).

FM

LPM

AM

WM

Mean plasmatic concentrations $\left(\mathrm{g} \mathrm{L}^{-1}\right)$

\begin{tabular}{|c|c|c|c|c|}
\hline Glucose & $0.95^{b} \pm 0.20$ & $0.99^{b} \pm 0.16$ & $1.43^{\mathrm{a}} \pm 0.45$ & $1.04^{b} \pm 0.43$ \\
\hline Triglycerides & $10.4^{\mathrm{b}} \pm 2.8$ & $10.3^{b} \pm 4.0$ & $10.8^{\mathrm{b}} \pm 3.4$ & $12.3^{\mathrm{a}} \pm 4.7$ \\
\hline
\end{tabular}

Specific enzymatic activities in the intestine (U . mg protein ${ }^{-1}$ )
Amylase
$0.90^{\mathrm{a}} \pm 0.39$
$0.94^{\mathrm{a}} \pm 0.36$
$0.66^{b} \pm 0.17$
$0.89^{\mathrm{a}} \pm 0.27$

Maltase*

$0.47^{b} \pm 0.14$

$0.52^{b} \pm 0.14$

$0.72^{\mathrm{a}} \pm 0.23$

$0.52^{b} \pm 0.26$

$*_{\text {in the brush border membrane of enterocytes }}$ 


\section{Table 4}

SIMPER overall average dissimilarities (\%) and ANOSIM (Bonferroni-corrected $p$ values in italics) between the mean bacterial profiles of mucosal and faecal samples of dietary groups by the end of the experiment (n.s.: not significant).

\begin{tabular}{|c|c|c|c|c|}
\hline & FM & LPM & AM & WM \\
\hline \multicolumn{5}{|c|}{ Mucosal samples } \\
\hline Over & rities & & \multicolumn{2}{|c|}{ ANOSIM $\left(\mathrm{R}=0.233, p<0.0001^{* * *}\right)$} \\
\hline FM & - & $0 * * *$ & $0.0006 * * *$ & $0.0048 * *$ \\
\hline LPM & 49.5 & - & $0^{* * *}$ & $0^{* * *}$ \\
\hline AM & & 52.6 & - & $0.0012 * *$ \\
\hline WM & & 52.4 & 53.7 & - \\
\hline \\
\hline \multicolumn{3}{|c|}{ Overall average dissimilarities (\%) } & \multicolumn{2}{|c|}{ ANOSIM $\left(\mathrm{R}=0.307, p<0.0001^{* * *}\right)$} \\
\hline FM & - & $0^{* * *}$ & $0.006 * *$ & 0.2 n.s. \\
\hline LPM & 57.0 & - & $0 * * *$ & $0^{* * *}$ \\
\hline AM & 49.3 & 59.8 & - & $0.0192 *$ \\
\hline WM & 54.6 & 58.5 & 53.9 & - \\
\hline
\end{tabular}

*One week before the end of the experiment 


\section{Table 5}

Identification of the OTUs with similar sequences found in GenBank.

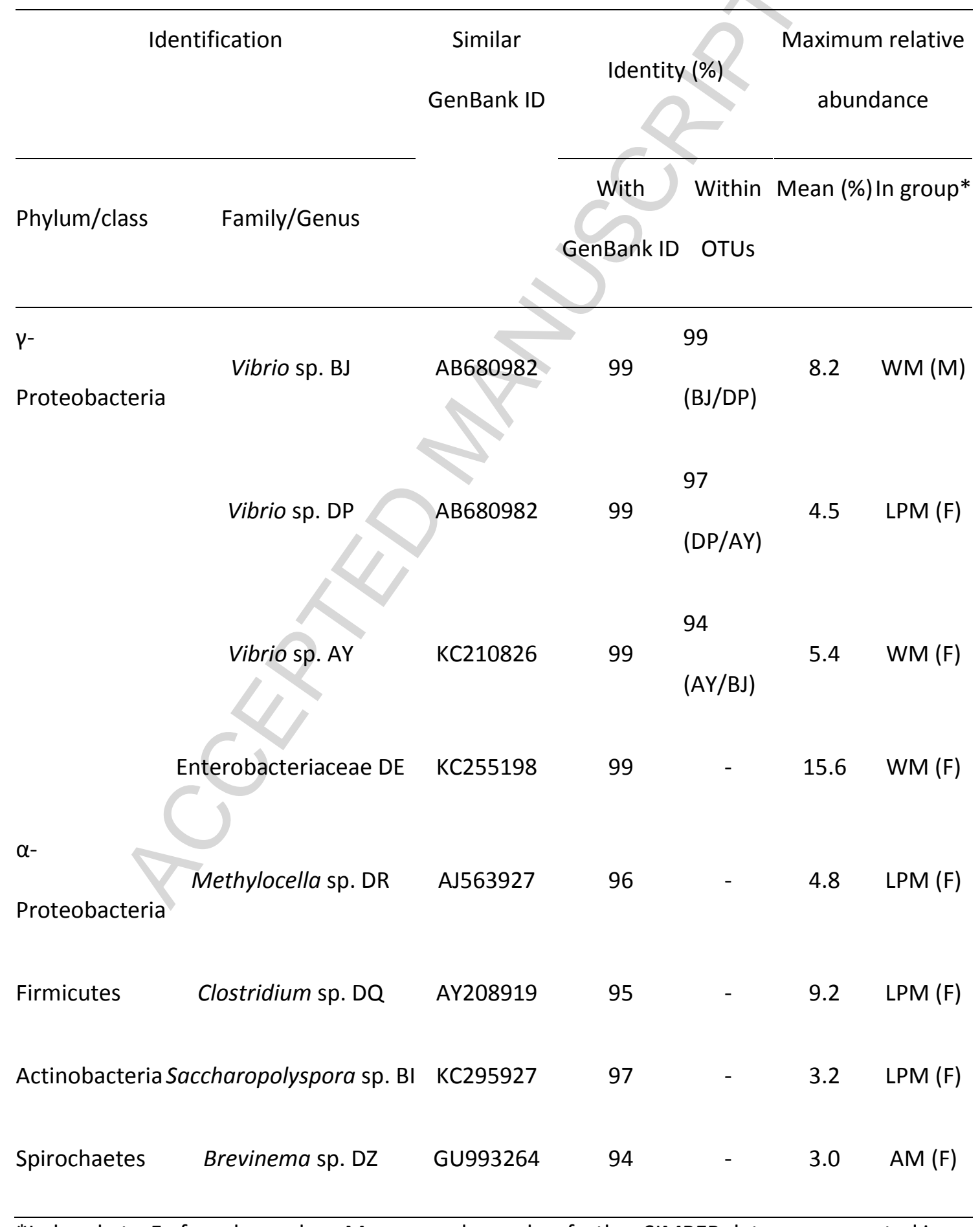

\footnotetext{
*In brackets, $\mathrm{F}$ : faecal samples ; $\mathrm{M}$ : mucosal samples; further SIMPER data are presented in Supplementary Tables S1 and S2
} 


\section{Table 6}

Acetate production in the faecal samples of dietary groups one week before the end of the experiment ( $\mathrm{mM} \pm \mathrm{SE}$; post-hoc test: Tukey after ANOVA; $p<0.001)$.

\begin{tabular}{cccc}
\hline FM & LPM & AM & WM \\
\hline $1.3^{\mathrm{b}} \pm 0.2$ & $1.9^{\mathrm{b}} \pm 0.3$ & $3.7^{\mathrm{a}} \pm 0.3$ & $3.3^{\mathrm{a}} \pm 0.4$ \\
\hline
\end{tabular}

